Rabaska

Revue d'ethnologie de l'Amérique française

\title{
Conseil québécois du patrimoine vivant
}

\section{Myriam Laflamme}

Numéro 1, 2003

URI : https://id.erudit.org/iderudit/201636ar

DOI : https://doi.org/10.7202/201636ar

Aller au sommaire du numéro

Éditeur(s)

Société québécoise d'ethnologie

ISSN

1703-7433 (imprimé)

1916-7350 (numérique)

Découvrir la revue

Citer ce document

Laflamme, M. (2003). Conseil québécois du patrimoine vivant. Rabaska, (1),

221-222. https://doi.org/10.7202/201636ar d'utilisation que vous pouvez consulter en ligne.

https://apropos.erudit.org/fr/usagers/politique-dutilisation/ 
QUÉBEC

Conseil québécois du patrimoine vivant

Maison de la francophonie

39 , rue Dalhousie

Québec (Québec) G1K 8R8

C. P. 1442, Québec (Québec) G1K 7G7
Téléphone : (418) 643-2772

Télécopieur : (418) 644-7670

Courriel : cqpv@cvfa.ca

Toile : www.cqpv.qc.ca

\section{Origine et mandat}

Le Conseil québécois du patrimoine vivant a pour mission de voir à la sauvegarde, à la promotion et à la transmission du patrimoine vivant de la collectivité. Il vise à regrouper et à représenter les personnes et les organismes préoccupés par la préservation, la recherche et la mise en valeur du patrimoine vivant, et à favoriser la réappropriation du patrimoine vivant par la communauté. Pour être membre du Conseil québécois du patrimoine vivant, il en coûte $25 \$$ pour une personne et $50 \$$ pour un organisme.

Cette mission se traduit par une série d'objectifs particuliers : 1. regrouper les personnes et les organismes engagés dans la préservation, la recherche et la mise en valeur du patrimoine vivant ; 2 . favoriser la représentativité des différentes régions, cultures, disciplines et secteurs d'interventions au sein du Conseil québécois du patrimoine vivant ; 3 . promouvoir la richesse et la diversité des valeurs humaines, culturelles, artistiques, sociales et économiques du patrimoine vivant à l'échelle locale, nationale et internationale ; 4. encourager un processus de développement du patrimoine vivant du Québec en suscitant des activités de sauvegarde, de conservation, de documentation, de recherche, d'information, de concertation, de formation, de réappropriation, de diffusion, de mise en valeur et de transmission ; 5. représenter et défendre les intérêts des personnes et des organismes dans la sauvegarde, la préservation et la mise en valeur du patrimoine vivant au Québec.

\section{Activités}

Le Conseil québécois du patrimoine vivant fut créé à la suite des États généraux du patrimoine vivant tenus à Québec en juin 1992. Depuis, il a accompli les actions suivantes dans les champs de ses compétences. Le CQPV a présenté des mémoires devant les commissions suivantes : Commission nationale sur l'avenir du Québec; Commission des États généraux sur l'éducation ; Commission de la culture : autoroute de l'information ; Ministère 
de l'Éducation : formation continue ; Comité permanent du patrimoine canadien; Groupe de réflexion sur l'avenir du Musée des arts et traditions populaires du Québec; Groupe-conseil chargé d'élaborer un projet de politique du patrimoine culturel.

Il a aussi préparé des publications : bulletins de liaison trimestriels Paroles, Gestes et Mémoires ; Permettre la mémoire au monde (Congrès de fondation); Colloque sur l'inventaire national du patrimoine vivant ; Le patrimoine vivant : transmission et développement; Tout ce que vous avez toujours voulu savoir sur le patrimoine vivant ; Partenaire, en Beauce pour une corvée de rêve; La Grande Criée d'automne au Saguenay/Lac-SaintJean; Forger l'avenir du patrimoine vivant.

Dix rassemblements annuels ont eu lieu à Montréal, Québec, Drummondville, Sainte-Marie de Beauce, Jonquière, Trois-Rivières, SaintMarc-sur-Richelieu, Fleurimont, Montmagny et celui de cette année se tiendra à Québec en novembre 2003.

Le CQPV a enfin mis sur pied en 2000 le Réseau MémoArt, un projet qui a pour but de réseauter des événements et festivals en patrimoine vivant dans le domaine de la musique, de la danse, du conte et des métiers traditionnels. Cette année, le réseau comprend treize festivals qui se tiennent de la mi-mai à la fin octobre. Pour plus de renseignements, vous pouvez consulter notre site : www.memoart.qc.ca.

Myriam LAFLAMME 